\title{
HISTOLOGICAL DIFFERENTIATION BETWEEN PHAEOCHROMOCYTOMA AND MELANOMA OF THE SUPRARENAL GLAND
}

\author{
BY \\ JOHN C. DICK, GRACE M. RITCHIE, AND HENRY THOMPSON \\ From the Department of Pathology; Stobhill Hospital, Glasgow
}

(RECEIVED FOR PUBLICATION OCTOBER 20, 195 )

Two patients presented with suprarenal tumours of similar macroscopic appearance and with some histological features in common. The final diagnosis in each case, however, was different; one was a typical phaeochromocytoma, while the other was believed to be a primary melanoma of the suprarenal. This paper illustrates the pathology of the two tumours, showing the difficulties encountered in their differentiation. The clinical histories of the two patients are of great interest and are described fully by Slessor et al. (1955) and Slessor and MacLeod (1955).

\section{First Case Report}

J. A., a man aged 49 years, presented with a history of episodes of shivering, diarrhoea, and vomiting: a large tumour was felt above the left kidney. The histamine test and blood assays for adrenaline were positive. At operation on May 24, 1951, a large tumour was removed from the site of the left suprarenal gland. The patient recovered satisfactorily but, on re-testing with histamine, a positive response was still obtained. He was able to return to work and remained symptomfree and normotensive but was kept under observation. Eighteen months later a mass was found in the left side of the neck. This mass, with attached thyroid tissue, was removed at operation on October 22, 1953. Again, the patient recovered satisfactorily and is now back at work.

The abdominal tumour was smooth and ovoid, measuring $12 \times 10 \times 10 \mathrm{~cm}$. and weighing $410 \mathrm{~g}$. (Fig. 1). It contained cystic spaces of varying sizes with dark brown grumous fluid. The solid parts consistęd of soft, greyish pink tissue with many small areas of old and recent haemorrhage which gave a reddish brown appearance to the whole mass. A portion of the tumour was sent for biological assay and was found to contain $1.75 \mathrm{mg}$. adrenaline and $10.75 \mathrm{mg}$. noradrenaline per $\mathrm{g}$. of fresh tumour.

Histologically, the tumour was surrounded by a thick, dense fibrous capsule through which tumour cells did not penetrate at any point. Clusters of refractile yellowish to dark brown pigment granules, presumably in crushed macrophages, were present in the inner layers. Outside the capsule, compressed remnants of suprarenal cortex were seen.

The tumour tissue was cellular, with large areas of haemorrhage but with little necrosis. The cells were arranged in solid masses (Fig. 2), often broken up by sinusoids or areas of haemorrhage: in a few areas, whorls and columins of cells were found. In still other areas, the cellular pattern of the suprarenal cortex was simulated (Fig. 3). The cells were of various types: the majority (Fig. 2) were large, polygonal, or round with a slightly basophilic, finely vacuolated cytoplasm and large round or oval, vesicular nuclei: among these cells, there were sinusoids with no reticulin lining. In many parts of the tumour these cells were not pigmented: in heavily pigmented areas (see Fig. 13) some of the tumour cells contained fine refractile granules of light to dark brown pigment, though most of the pigment was present in macrophages lying in the sinusoids, in the interstitial tissue or in fibrous trabeculae and showed as large granules of a light yellowish brown. Other cells were smaller, more eosinophilic and non-vacuolated, with slightly smaller, oval, vesicular nuclei: these cells occurred in strands (Fig. 4) throughout the tumour, mostly round small blood vessels and capillaries. A third type of cell found only very occasionally was suggestive of a ganglion cell (Fig. 5): no other nervous elements were found in the tumour.

Small or large angular cells with much more basophilic cytoplasm and solid oval nuclei were occasionally observed, compressed between the larger cells. With chrome fixation and Sevki's modification of Giemsa's stain, the cytoplasm of these angular cells stained diffusely green. With a similar technique, in some of the main type of cells, the small green granules typical of chromaffin 
FIG. 1-Phaeochromocytoma (Case 1), cut surface. Smooth ovoid tumour with two large cystic spaces: tumour tissue greyish pink with many small haemorrhages. $\times \frac{1}{2}$.

FIG. 2.-Phaeochromocytoma: field showing large, polygonal or round cells with vesicular nuclei: masses of cells broken up by sinusoids. Haematoxylin and eosin. 100.

FIG. 3.-Phaeochromocytoma: field in which the cell pattern simulates the suprarenal cortex. Haematoxylin and eosin. $\times 120$.

FIG. 4.-Phaeochromocytoma: strands of smaller, more eosinophilic cells round small blood vessels. Haematoxylin and eosin. $>60$.

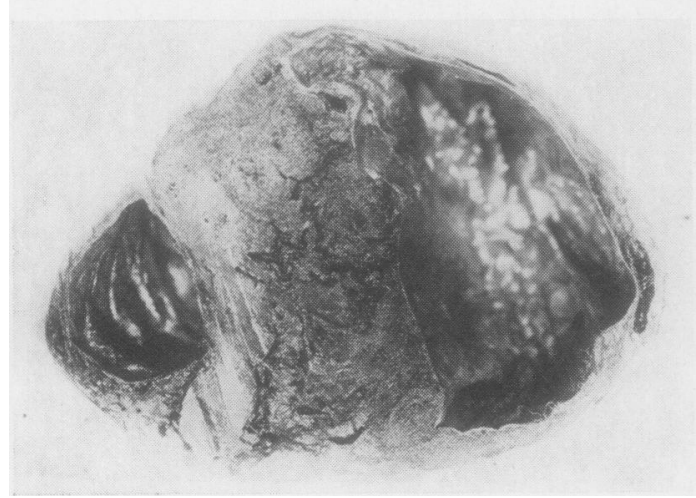

FIG. 1

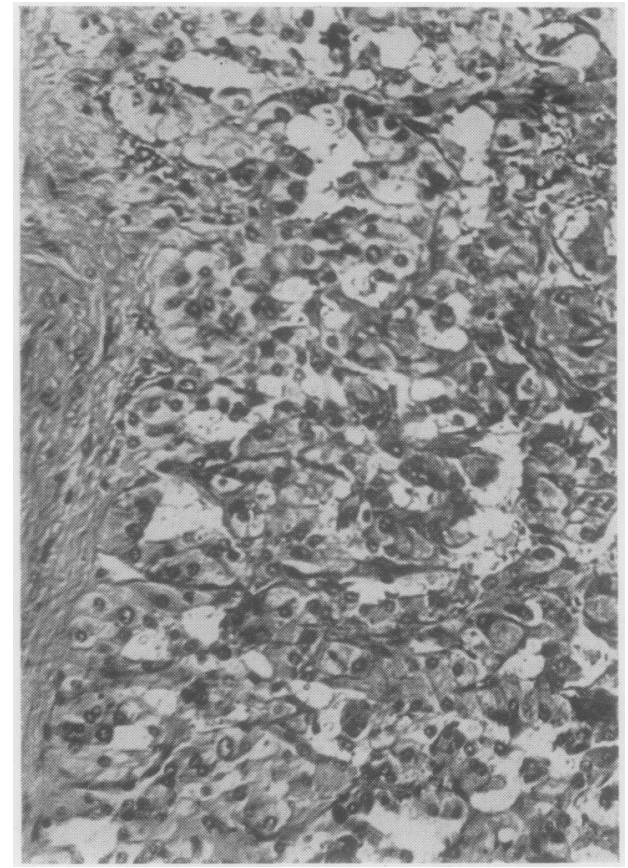

FIG. 3

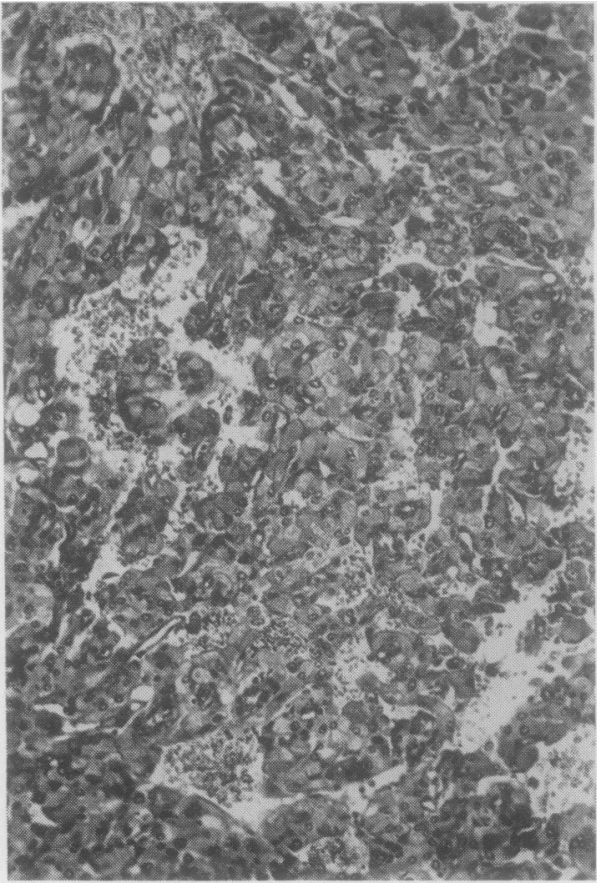

FIG. 2

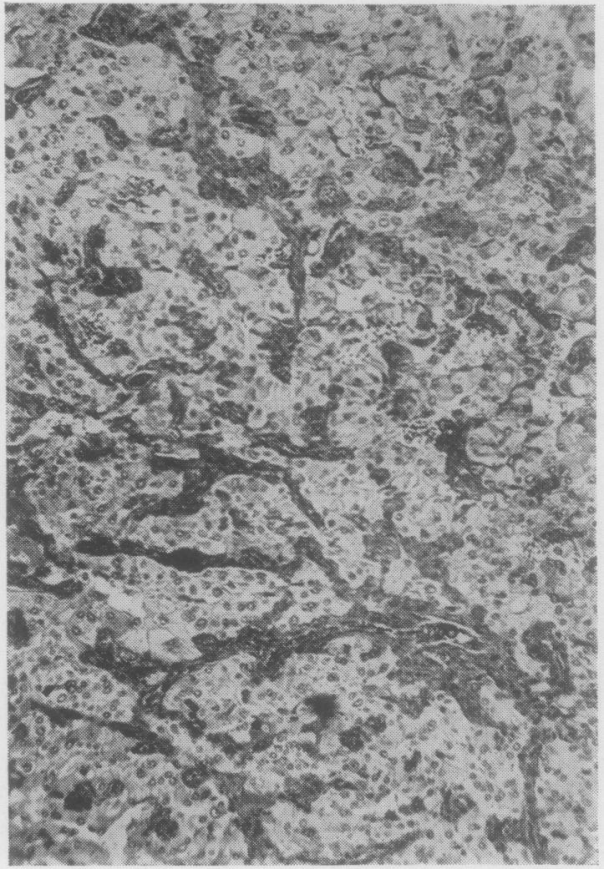

FIG. 4 


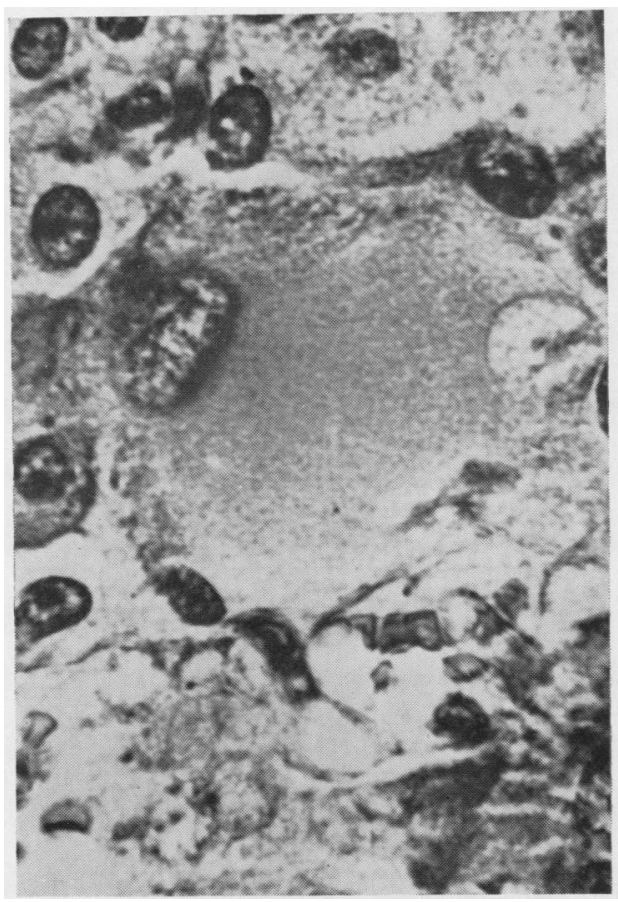

FIG. 5. -Phaeochromocytoma: ganglion-type cell. Haematoxylin and eosin. $\times 600$.

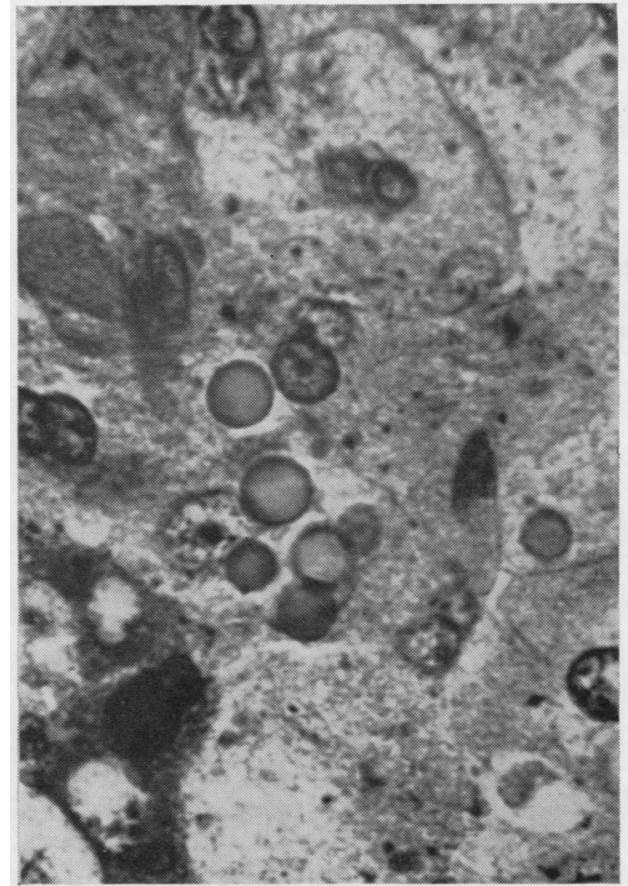

FIG. 6.-Phaeochromocytoma: cluster of jround hyaline bodies in cell cytoplasm. Haematoxylin and eosin. $\times 600$.

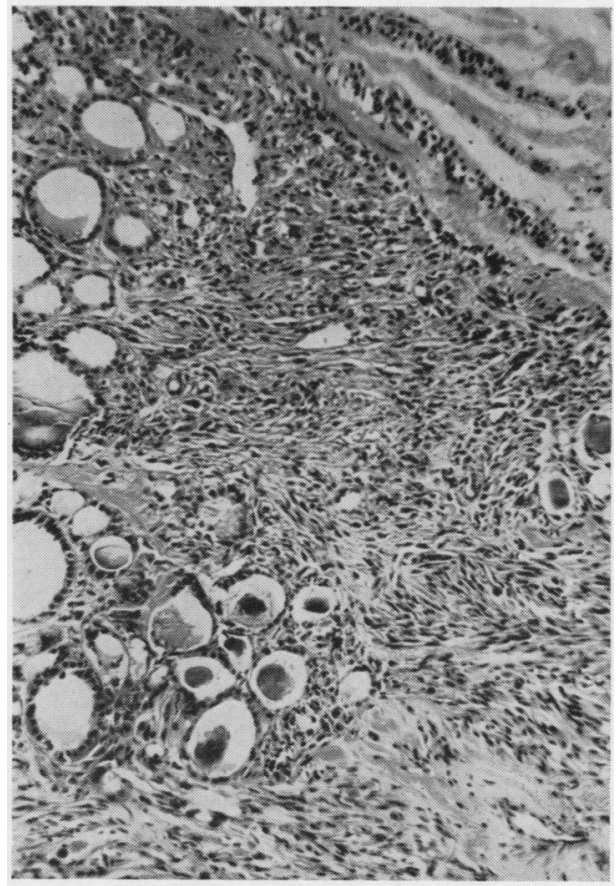

FIG. 8.-Carcinoma of thyroid: spindle-shaped cells infiltrating normal acini. Haematoxylin and eosin. 
were seen and the fluid in some of the sinusoids also gave a green colour. Other granules remained yellowish-brown similar to those in macrophages in the capsule and sinusoids. Also in the cytoplasm of some of the main cells, there were round, hyaline bodies of varying sizes (Fig. 6): they were strongly eosinophilic, stained well with fuchsin and phloxin, and occurred singly or in clusters in individual cells or in groups of cells.

From the above histological characteristics, the typical clinical history and biological assay, this tumour was a true phaeochromocytoma of the suprarenal medulla.

The cervical tumour was a somewhat flattened pinkish-grey mass, $6 \times 4 \times 3 \mathrm{~cm}$.: on section, the outer third consisted of firm grey tissue with colloid material, while the centre was occupied by irregularly whorled, softer, pinkish-white tissue.

The histological picture was that of carcinoma developing in a simple adenoma of the thyroid (Figs. 7 and 8).

\section{Second Case Report}

F. P., a man aged 62 years, presented with a slowly growing mass of two years' duration in the right groin: it was painless and no other lymphadenopathy or abnormal physical sign could be detected. At operation (July 9, 1952), it appeared to be a melanoma. Full clinical investigation at that time, however, failed to disclose a primary tumour in skin, mucocutaneous junctions, or eyes. In view of the superficial histological similarities to the tumour in the first case, the possibility of a phaeochromocytoma was raised, but clinical investigation gave no evidence of such. The patient remained perfectly well and at work until August, 1953, when throbbing pain developed in the right side and numerous bluish nodules appeared in the skin and subcutaneous tissues. One such nodule was excised from the left groin on September 19, 1953. Repeated search for a primary melanoma in skin or eye again gave negative results. His generai condition now deteriorated rapidly and he died on October 19, 1953.

Necropsy showed a somewhat emaciated elderly male with multiple subcutaneous bluish nodules, most numerous over the shoulders and anterior chest wall: section of the skin showed that, while most were under the true skin, a few were in its deeper layers although none involved the epidermis: they consisted of soft brown and white tumour nodules with areas of necrosis and haemorrhage. None of these nodules had been apparent at the time of his first admission, 18 months before. Operation scars were seen in both groins. Scars from shrapnel wounds from the 1914-18 war were present on both legs, one $10 \mathrm{~cm}$. in length over the right tibia where an operation had been required, the others small $(1 \mathrm{~cm}$. in length) on the back of the left leg. No other scars were found and this agreed with his story that he had had no other operations. Both legs were oedematous. The finger- and toe-nails were all removed and the subungual areas examined carefully for a possible primary melanoma, with negative result. The whole skin surface and all mucocutaneous junctions were again examined meticulously without success.

Several small pigmented tumour deposits $(2 \mathrm{~mm}$. in diameter) were present in the heart and pericardium, which were otherwise normal. Chronic fibroid phthisis was found in the upper lobes of both lungs and the lower lobes showed small areas of early infarction (due to emboli from thrombosed leg veins); the hilar glands showed neither caseation nor tumour infiltration, but one anterior mediastinal

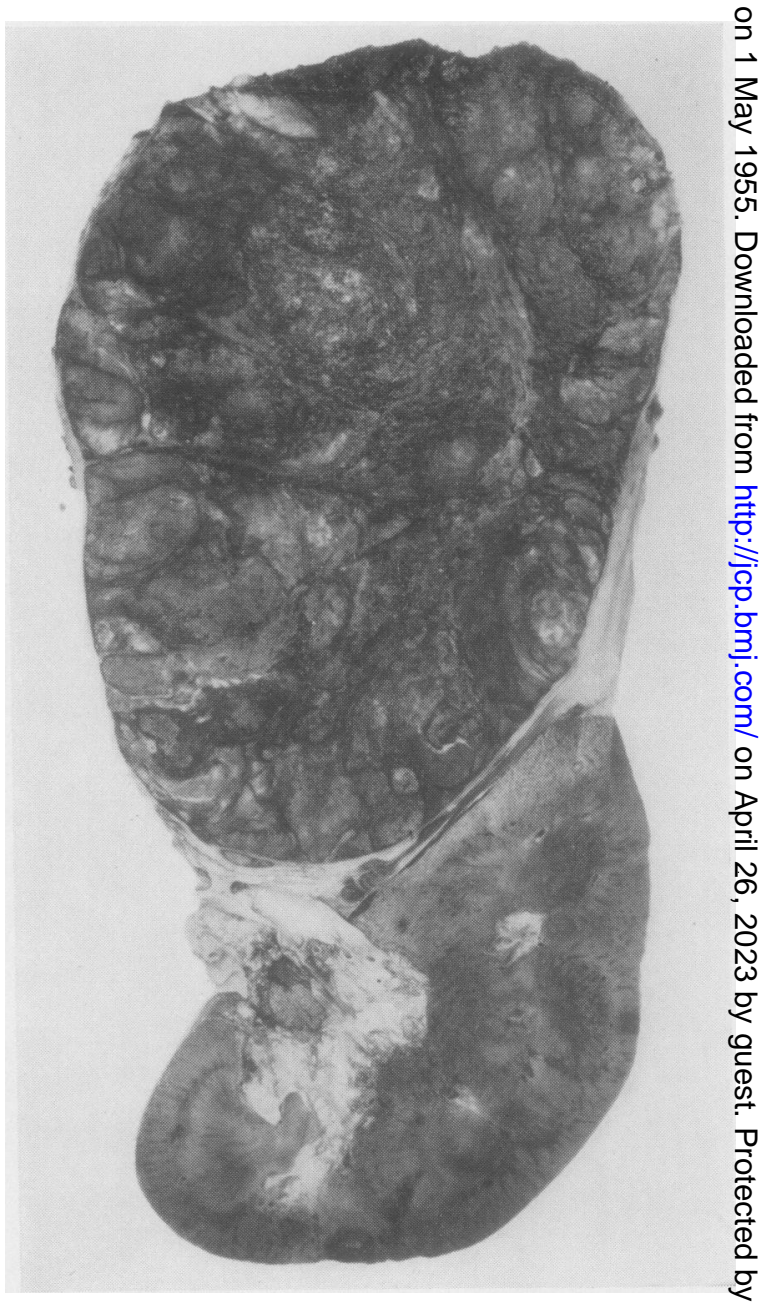

FIG. 9.-Melanoma of suprarenal (Case 2), posterior cut surface. Large lobulated tumour with grey, red, and brown areas. $\times 3.5$ 
gland was enlarged to $2 \mathrm{~cm}$. in diameter with pigmented tumour tissue. Two small pigmented tumour deposits were seen in the right pleura, posteriorly, while adhesions were found over both upper lobes.

The peritoneum contained $500 \mathrm{ml}$. clear yellow fluid and several small secondary tumour deposits were present. The mesenteric glands showed slight enlargement with pigmented tumour. The stomach and intestines were normal. The liver was enlarged due to terminal congestion, but no metastases were found in it: the gall-bladder and bile ducts were normal. The spleen was soft and congested and no metastases were seen. One nodule $(2 \mathrm{~cm}$.) of pigmented tumour was present in the left kidney, none in the right. The bladder had two small ( $2 \mathrm{~mm}$.) secondary nodules in the submucosa. No secondary tumour was found in the marrow of vertebrae, ribs, or skull.

The right suprarenal was replaced by a large lobulated tumour, $17 \times 12.5 \times 10 \mathrm{~cm}$., weighing 900 g., with a smooth surface (Fig. 9). On section, the mass was trabeculated and consisted of soft, brownish-black tissue with extensive areas of necrosis and haemorrhage: no cysts or crystals were present. To the naked eye, no suprarenal tissue was obvious. The left suprarenal was slightly enlarged and contained one macroscopic nodule $(2 \mathrm{~cm}$.) of pigmented tumour tissue.

In the meninges, one nodule $(0.5 \mathrm{~cm}$.) of pigmented tumour was present overlying the left sensory cortex: no other abnormality was found. In the brain, several small nodules (c. $0.4 \mathrm{~cm}$.) were scattered throughout both cerebral hemispheres with one larger deposit $(2.5 \mathrm{~cm}$.) at the posterior horn of the left lateral ventricle. The orbits showed no tumour deposits. Both eyeballs were bisected, examined carefully in situ and the posterior halves removed for histological examination, all with negative results for any tumour tissue.

Histology of Tumour of Groin.- - This, apparently encapsulated, measured $6 \times 5 \times 3 \mathrm{~cm}$., and was brown, with black areas. On section, white and brown nodules of tumour tissue were present round the periphery with necrosis and haemorrhage in the centre. An attempt at biological assay on a portion of the tumour failed for technical reasons.

The surrounding tissue consisted of compressed and fibrosed lymphoid tissue, infiltrated in parts by nodules of tumour showing great variation in cellular detail. In infiltrating areas (Fig. 10), the tumour tissue was composed of sheets of large

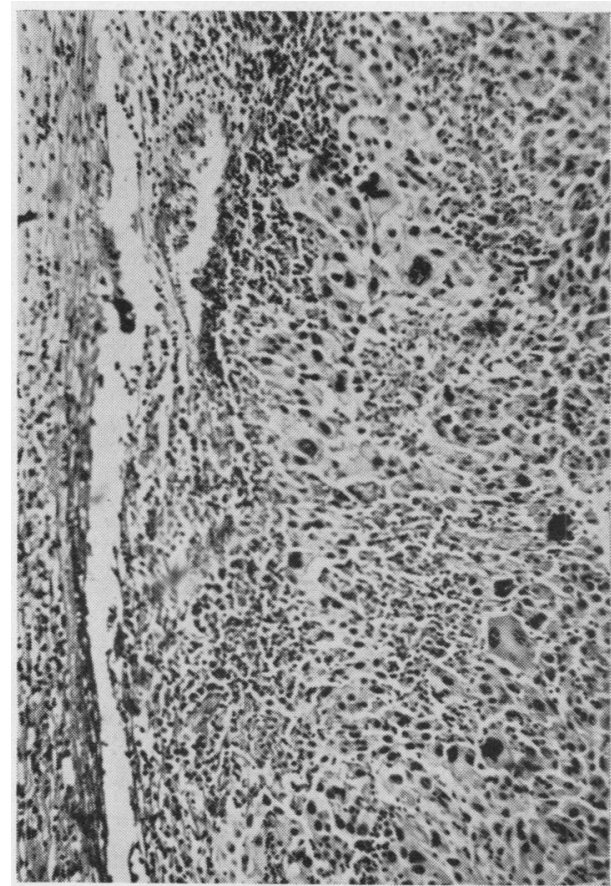

FIG. 10.-Melanoma, first biopsy, showing infiltration of lymphoid tissue by irregular cells with irregular nuclear figures. Haematoxylin and eosin. $\times 100$.

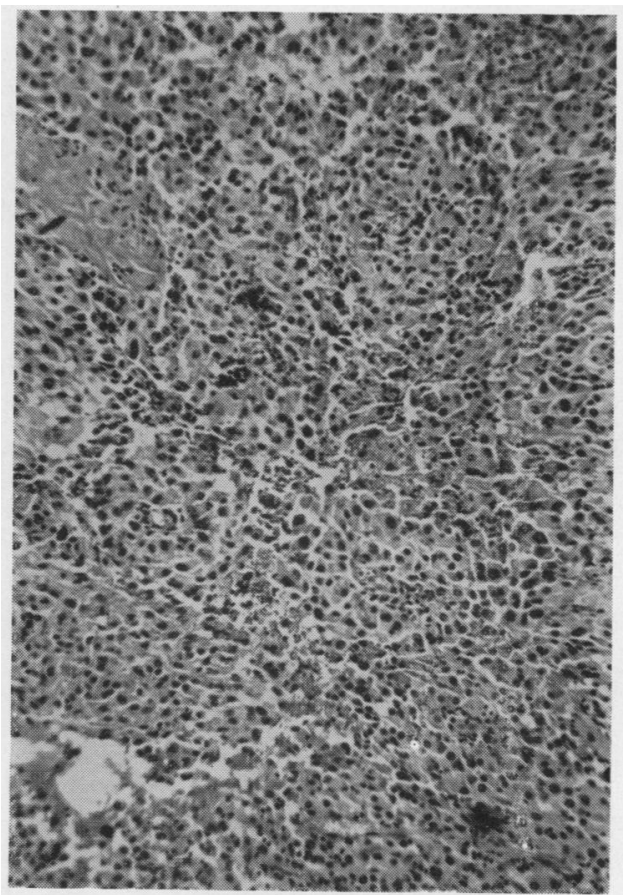

FIG. 11.-Melanoma, first biopsy, showing ill-defined whorls of tumour cells and irregular sinuses. Haematoxylin and eosin. $\times 100$. 
irregular polygonal cells with foamy or finely granular cytoplasm and large hyperchromatic oval nuclei in which mitotic figures were fairly numerous: irregular giant cell forms were found. In the necrotic areas, the surviving cells were arranged mostly in whorls in which the central cells were small, irregular, and deeply basophilic, while around them were medium-sized or large, irregular, or polyhedral cells, often in layers like transitional-cell carcinoma: in a few areas, however, there appeared to be an acinar arrangement around sinuses without reticulin lining (Fig. 11) and the cells closely resembled those seen in parts of the phaeochromocytoma. Pigment was present in considerable amount, though with peculiar distribution: it was present in all types of cell described above in some parts and completely absent from similar cells elsewhere: it occurred as fine black dots in the cytoplasm of some cells or as large yellowish-brown granules in others. It was present also in the edges of the dense fibrous trabeculae round the periphery, here mostly as large brown or black granules in compressed macrophages. None of the pigment gave the iron reaction.

In view of the presence of lymphoid tissue, this was a secondary tumour in the inguinal glands. With the knowledge that no primary melanoma could be found clinically, and because of the resemblance of some parts of the tumour to the phaeochromocytoma in the first case, post-chroming and Sevki's stain for adrenaline precursor were tried on the sections and the granules stained bright green. The fallacies of this technique were not realized at that time and it was suggested that the tumour was a secondary phaeochromocytoma or a secondary carcinoma from a primary in the suprarenal.

Subcutaneous Nodule from the Inguinal Region.This was a greyish-black nodule, the histological appearances of which were similar to those in the previous biopsy. It was realized by this time that post-chroming of tissues allowed non-chromaffin pigment with reducing characteristics, e.g., melanin, to stain green with Sevki's method and it was now accepted that both the excised tumours were secondary malignant melanomata.

Tumour of Right Suprarenal.-The tumour of the right suprarenal showed extensive areas of necrosis and much haemorrhage. Some sections from the periphery showed a broad, dense, fibrous capsule, containing abundant refractile dark brown pigment: in places outside this capsule, small compressed and fibrosed remnants of suprarenal cortex were found. Other peripheral sections showed tumour cells directly infiltrating loose fibrous and fatty tissue. Apparently, this tumour had been growing slowly but had recently assumed more rapidly infiltrating characteristics.

The tumour was composed of masses of cells $\frac{\text { ? }}{0}$ arranged in sheets and lobules with fairly numerous $\frac{\mathrm{C}}{\mathrm{O}}$ capillaries and enclosed in bands of dense or loose $\frac{\bar{\sigma}}{\bar{\rho}}$. fibrous tissue. The cells varied greatly in size and $\overparen{\nabla}$ shape (Fig. 12), mostly large and polygonal, but $\frac{\varrho}{\Omega}$ without a predominant cell type: the nuclei were $\$$ large and round or oval, hyperchromatic and with $\overrightarrow{0}$

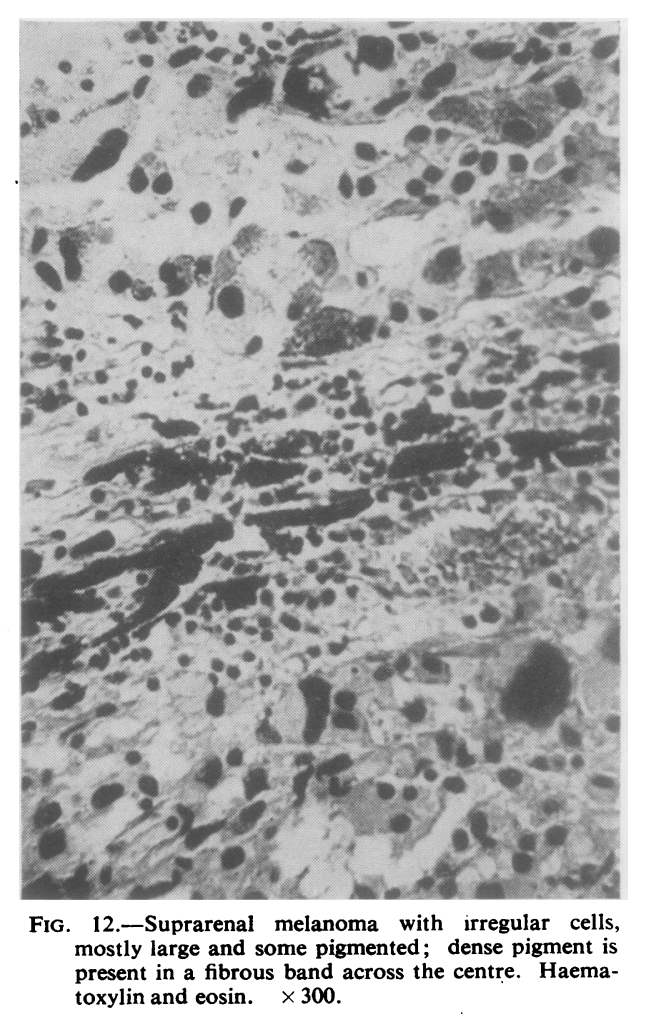

many mitotic figures, some of which were bizarre. In the centres of the lobules and alongside smallo blood vessels, there were small rounded basophilic N cells with small dense nuclei as in the groin biopsy. N In many areas, some of the large cells contained ${ }_{\sigma}$ fine granules of dark brown pigment, sometimes diffusely dispersed, sometimes only in parts of the cells. In these areas, larger granules of the pigmento were concentrated in cells either centrally or at the periphery and in the surrounding fibrous tissue:0 details of these latter cells were completely obscured $\stackrel{\vec{\Phi}}{\mathbb{Q}}$ by the pigment and they were probably. macro- $\frac{?}{\mathbb{0}}$ phages. In several of the loose fibrous areas, the presence of deeply pigmented cells with no tumour near suggested that some areas of tumour hado 
undergone necrosis, leaving the pigment in macrophages. In some of the tumour cells, rounded, hyaline, slightly basophilic bodies were seen, but only near necrotic areas, and they showed none of the staining characteristics of the eosinophil hyaline bodies in the phaeochromocytoma of the first case: they appeared to be a degenerative phenomenon.

In the left suprarenal, the mass of tumour seen naked-eye was situated in the medulla, with some fairly dense fibrosis between it and the cortex, but there was also recent infiltration around in some parts. Several small foci of tumour cells were scattered throughout the cortex and medulla. The appearances suggested that the tumour here was secondary to that in the right suprarenal. The histology of all the other deposits throughout the body was similar to that of the mass in the right suprarenal.

It was now believed that the diagnosis was either a primary melanoma of the right suprarenal or, if such a primary is not acceptable (Willis, 1948), a primary pigmented tumour of the suprarenal, e.g., a phaeochromocytoma, in which the physiological activity had been replaced by malignant activity. The final answer appeared to lie in the nature of the pigment, which looked very similar to that in the phaeochromocytoma, and so further investigation of this point was undertaken.

\section{Further Investigation of Pigment Histology}

Iron.-The great bulk of the pigment under investigation did not give a positive Prussian blue reaction and so did not contain free iron. Only a few isolated granules in each tumour gave a positive reaction, compatible with haemorrhages into the tumours.

Chromaffin Reaction.-In the suprarenal tumours from both cases the colour was predominantly brown and it was difficult to say if further darkening took place during fixation with chrome salts. On subsequent staining with Sevki's modification of Giemsa's stain, in the first case most of the small and a few of the large granules stained green though the majority of the large granules remained light yellowish-brown: fine green granules were also seen in some cells which showed little or no obvious pigmentation without this technique. This suggested the presence of two types of pigment, one, the chromaffin, occurring mainly as fine granules, and the other (present in much greater proportion), occurring as fine and large granules. In the second case, on the other hand, both small and large pigment granules stained green. Sections of the first biopsy from blocks which had not originally been fixed in a chrome solution, but chromed after formalin fixation, also showed these fine green granules. Blocks from two known melanomata were also chromed after formol-corrosive fixation and sections stained by Sevki's method: the melanin granules stained green. This finding emphasizes that the chromaffin reaction is the original darkening in the chrome fixative and that the later staining by Sevki's method is not specific for granules of chromaffin. This point must be noted in a pigmented tumour in which the diagnosis of phaeochromocytoma is a possibility.

Periodic - Acid - Schiff Technique. - With the periodic-acid-Schiff (P.A.S.) technique, a distinct difference was observed in the pigment of the tumours from the two patients. In the first case, both fine and large granules of pigment gave no reaction, although the cytoplasm of the cells was occasionally positive. Thus neither type of pigment in the phaeochromocytoma was positive with P.A.S.

In the second case, the fine cellular granules remained brown, though sometimes the cell cytoplasm stained pink or red: the great majority of the large granules in cells in the tumour masses and in the stroma were very definitely reddish-brown: this behaviour of the pigment would suggest that it might be melanin, which, according to Pearse (1953), gives a positive P.A.S. reaction only when in melanophages. In sections from the control melanomata, the pigment behaved in a similar fashion.

Bleaching with $10 \%$ Hydrogen Peroxide.-The results obtained by using this technique (Pearse, 1953) showed a sharp differentiation in the type of pigment in the two cases. Most of the pigment from the first case was not bleached after $\mathbf{4 8}$ hours' treatment, both the large granules and some of the fine particles remaining unaffected (Fig. 13). This resistance to bleaching excluded melanin as being the bulk of the pigment in the phaeochromocytoma and further suggested that it was not of simple chromaffin type. The pigment from the second case, on the other hand, showed practically complete bleaching at 48 hours (Fig. 14), most of the colour coming out between 24 and 48 hours, thus confirming that the pigment was a melanin. This observation was corroborated by simultaneous control tests on pigment from the two known melanomata.

Solubility.-While using Gordon and Sweet's method of staining reticulin for the arrangement of the tumour cells, a clear difference in the reaction of the pigments from the two cases was noticed. In the first case, while most cells showed fine argyrophil granules (presumably chromaffin), large 


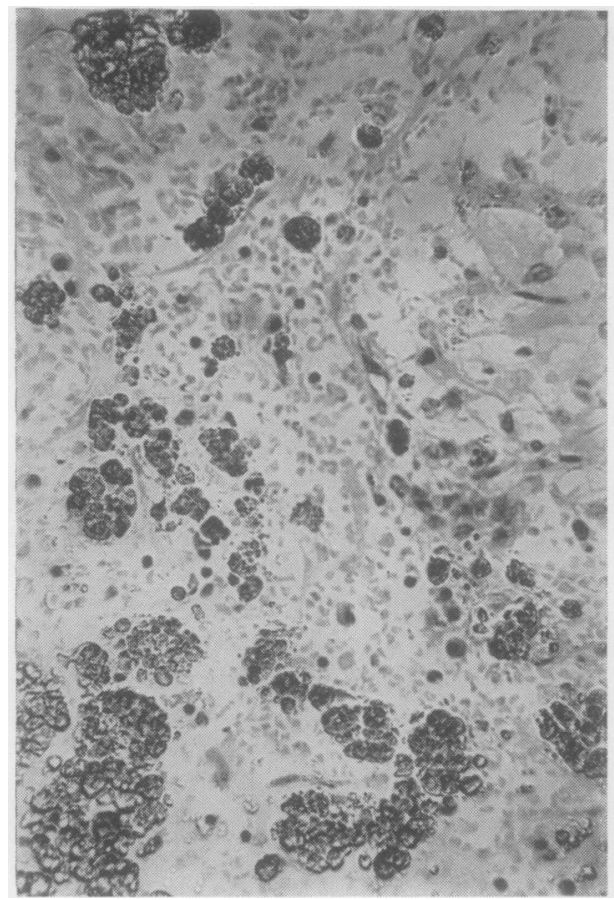

FIG. 13.-Phaeochromocytoma: pigment granules resisted bleaching for 48 hours with $10 \%$ hydrogen peroxide. Dilute carmalum stain. $\times 300$.

granules of pigment were not affected by the procedure, but remained refractile and yellowish-brown.

In the second case, and in the two known control melanomata, however, many of the small granules of pigment stained black, while others, especially the large granules, had disappeared completely. The interpretation of this finding appeared to be that some of the melanin granules showed argyrophilia while others were dissolved by the alkali used in this method. It would appear that when the pigment was present in macrophages it was somehow altered and gave a different reaction when subjected to alkali and to the P.A.S. technique.

\section{Discussion}

These two suprarenal tumours were both large, brown, and showed cystic or necrotic spaces. Histologically, compressed cortical tissue was found outside the capsules in both. The tumour cells showed great variety in size and shape and there was much pigment, mostly in macrophages in the capsules and trabeculae. Here the resemblances ended. For, in the first case, the cells were differentiated into several distinct types (Figs. 2, 4, and 5), the nuclei were well formed, and there was no evidence of malignancy. In the second case, the cells showed greater variety without distinct types

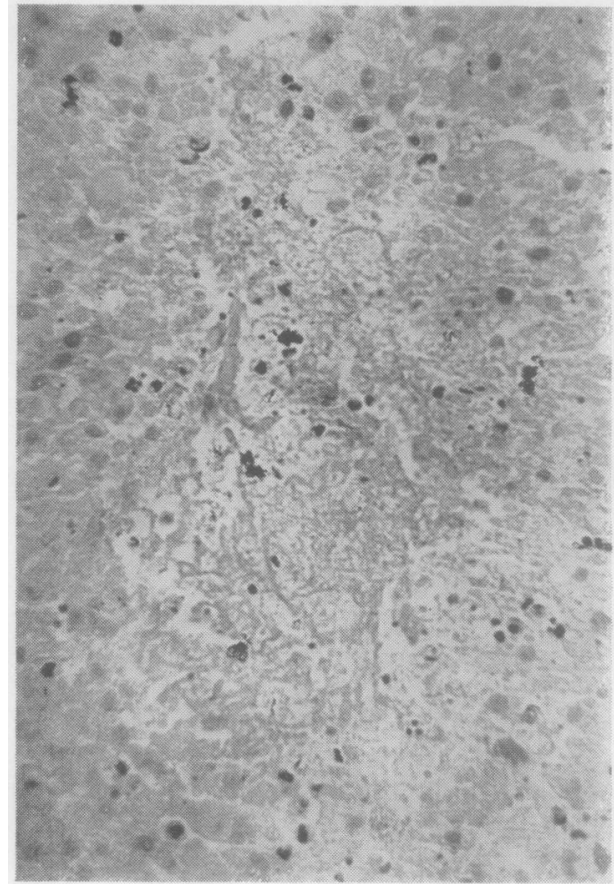

Fig. 14.-Suprarenal melanoma: great majority of pig. ment granules bleached after 48 hours in $10 \%$ hydrogen peroxide (cf. Fig. 12). Dilute carmalum stain. $\times 300$.

(Figs. 10, 11, and 12), the nuclei were often irre- $\frac{\mathrm{O}}{3}$ gular, and there was definite evidence of malignancy. Nevertheless, distinction between the two tumours? was very difficult, partly on account of the absence of biological assay in the second case, partly because? of the close chemical relationship between the pigments in the two cases.

From the clinical history of the first case and the histological and biological findings in the suprarenal tumour, it was a phaeochromocytoma. Only a few points require mention in view of the recent $D$ literature on the histology of this tumour (Blacklock, Ferguson, Mack, Shafar, and Symington, 1947; N Symington and Goodall, 1953). One was the presence of pigment: this is virtually ignored in $\mathcal{N}^{-}$ most descriptions of the tumour, though Blacklock $\mathrm{W}$ et al. described the tumour in their fourth case as light-brownish in colour and Hyman and Menchero

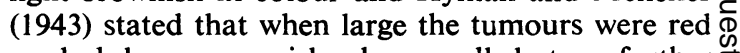
or dark-brown, greyish when small, but no further $\stackrel{?}{+}$ details of the pigment were given. Here, the nature $\frac{T}{0}$ of the pigment was investigated purely for compari- $\frac{0}{\mathbb{D}}$

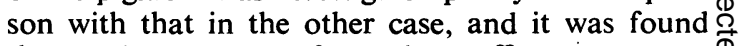
that a pigment apart from chromaffin was present $\stackrel{\mathbb{Q}}{\stackrel{2}{ }}$ with the following reactions: not sudanophil, not? containing free iron, negative to P.A.S., and not 0 bleached by hydrogen peroxide $(10 \%)$ in 48 hours. 
Thus it may be a type of lipo-pigment, perhaps similar to the granules in a ganglion cell (Pearse, 1953).

Another point of interest was the presence of hyaline bodies, intensely eosinophil, occurring singly or in clusters, in the cytoplasm of the cells. They stained strongly with acid fuchsin, phloxin, and eosin, were positive to P.A.S., not fatty, while with Sevki's stain the small ones were pink and the large ones green or blue, they took a counterstain with Gordon and Sweet's method for reticulin and were still present after 48 hours' bleaching with $10 \% \mathrm{H}_{2} \mathrm{O}_{2}$. They did not appear in any of Symington and Goodall's specimens, but were present in the tumour described by Beer, King, and Prinzmetal (1937), and Ewing (1928) states that they "are usually present" in phaeochromocytomata. They appeared to be similar to bodies found in some cells of the normal suprarenal cortex (Selye and Stone, 1950), though not compatible in morphology or in staining reactions with ingested red blood corpuscles, as these authors had suggested.

The final point about the first case was the persistence of symptoms after removal of the suprarenal tumour and the subsequent development of an adenocarcinoma of the thyroid. The association of these two tumours was first pointed out by Eisenberg and Wallerstein (1932), who reported one such combination in a review of 53 cases of phaeochromocytoma, and later by Symington and Goodall (1953), who found two others (Muntz, Ritchey, and Gatch, 1947, and Rothermich, 1952) in 283 cases of the same tumour, while Beer et al. (1937) reported a fourth, but in these the adenocarcinoma of thyroid presented first. The association appears to be more frequent than would occur by chance. The behaviour of the thyroid in patients with phaeochromocytoma is discussed fully by Slessor (1955).

The second case provided a much more difficult problem. At the time of the first biopsy, in view of the complete absence of any other clinical findings and with the histological resemblances to the tumour from the first case, especially the wrongly interpreted reaction to Sevki's staining method after chrome fixation, it appeared logical to suggest the possibility of a malignant phaeochromocytoma. This in itself would have been a rare occurrence; phaeochromocytoma is described as being "usually simple" (Cappell, 1951). Symington and Goodall (1953) accepted reports of only seven malignant examples though none had biological assays of the secondary tumour, while Willis (1948) cast doubt on all cases reported as malignant in view of the lack of biological assays. Robinson and Baker-
Bates (1954) reported a case of carcinoma of the suprarenal cortex which might easily have been mistaken for a malignant phaeochromocytoma, especially in view of the fact that a simple phaeochromocytoma may simulate the suprarenal cortex in parts (cf. our Fig. 3 and Robinson and BakerBates' Fig. 476A). Biological assay in their case, however, was negative and the histology did not show sufficient pleomorphism of the cells. In the present case, the clinical absence of any signs of hyperadrenalism made it extremely unlikely that such a specialized tumour could lose all its powers of adrenaline secretion in return for the property of malignant growth. The subsequent behaviour of the growth became typical of a melanotic tumour and this was confirmed by the histological features in conjunction with the reactions of the pigment.

This then raised the question of its being a primary melanoma of the suprarenal medulla. Willis (1948) cannot accept this as a primary site for melanoma unless strict requirements are satisfied. In this case, the skin and eyes had been searched repeatedly during life by competent clinicians on many occasions, and again at necropsy the examination was repeated with meticulous care: every nail was removed, the eyeballs opened, the pia-arachnoid examined, all without finding a possible primary growth in the other accepted sites. Muir's Text-book of Pathology (Cappell, 1951) gives the suprarenal as a site for primary melanoma, and Ewing (1928) quotes cases reported as melanosarcoma by Davidsohn, Goldzicher, Tuczek, and Maclachlan. From Maclachlan's (1915) description of his own case and his review of the earlier three, there is no doubt that similar precautions as to possible sources of a primary elsewhere were fully taken and these four closely resemble our own case. Smith (1927) has also described a similar growth, and, though he did not examine the eye-balls, the orbits were clear of tumour, and there is little doubt that his case was also primarily in the suprarenal. While there was considerable argument and disagreement as to the exact nature of the earlier tumours, the development of the medulla of the suprarenal from neuroectoderm provides a complete analogy for tumours from this site with skin melanomata, on the basis of Nicholson's (1922 and 1923) and Dawson's (1925) work as accepted by Willis (1948) and Cappell (1951).

Accordingly, we submit that this tumour was a primary melanoma of the suprarenal medulla.

\section{Summary}

Two patients had primary pigmented tumours in the suprarenal medulla: the histological character- 
istics with special reference to the pigment are described and compared.

In one patient, the tumour was a phaeochromocytoma-simple, with pleomorphism but distinct cell types: in addition to chromaffin, there was another pigment probably of the lipo-pigment group. The tumour was removed successfully. Eighteen months later, a carcinoma developed in a simple thyroid adenoma and was also removed with no recurrence to date.

In the other patient, two biopsies were performed, one from each groin, two years and six months before a primary melanoma of the suprarenal medulla was found at necropsy.

Some difficulties in the differentiation of pigmented suprarenal tumours are pointed out.

The authors wish to thank Dr. A. Slessor for his close clinical cooperation, Mr. James P. Galloway and Mr. R. Macleod for the surgical specimens, and their colleagues in the Department of Pathology. They are also indebted to Mr. Ian Mackie for technical and photographic assistance.

\section{REFERENCES}

Beer, E., King, F. H., and Prinzmetal, M. (1937). Ann. Surg., 106, 85 Blacklock, J. W. S., Ferguson, J. W., Mack, W. S., Shafar, J., and Symington, T. (1947). Brit. J. Surg., 35, 179.

Cappell, D. F. (1951). Muir's Text-book of Pathology, 6th ed. pp. 247, 1058. Arnold, London.

Dawson, J. W. (1925). Edinb. med. J., 32, 501.

Eisenberg, A. A., and Wallerstein, H. (1932). Arch. Path. (Chicago), 14,818 .

Ewing, J. (1928). Neoplastic Diseases, 3rd ed., p. 820. Saunders, Philadelphia and London.

Hyman, A., and Mencher, W. H. (1943). J. Urol., 49, 755.

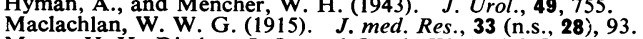

Muntz, H. H., Ritchey, J. O., and Gatch, W. D. (1947). Ann. intern. Med., 26, 133.

Nicholson, G. W. (1922). Guv's Hosp. Rep., 72, 333. (1923). Ibid., 73, 37.

Pearse, A. G. E. (1953). Histochemistry, Theoretical and Applied, pp. 372, 343, 342, and 370 . Churchill, London.

Robinson, P. L., and Baker-Bates, E. T. (1954). Brit, J. Surg., 41 399 .

Rothermich, N. O. (1952). Ann. intern. Med., 36, 157.

Selye, H., and Stone, H. (1950). On the Experimental Morphology of the Adrenal Cortex. Thomas, Springfield, Ill., and Blackwell, Oxford.

Slessor, A. In preparation. et al. In preparation.

Smi and MacLed, R. G. In preparation

Smith, R. M. (1927). Med. J. Aust., 1, 683.

Symington, T., and Goodall, A. L. (1953). Glasg. med. J., 34, 75.

Willis, R. A. (1948). Pathology of Tumours, pp. 873, 915. Butter worth, London. 